\title{
Role of Renal Sympathetic Nerves in Mediating Hypoperfusion of Renal Cortical Microcirculation in Experimental Congestive Heart Failure and Acute Extracellular Fluid Volume Depletion
}

\author{
Valentina Kon, Aida Yared, and lekuni Ichikawa \\ With the technical assistance of $\mathbf{M}$. Laurette Hughes \\ Laboratory of Renal Physiology, Department of Medicine, The Children's Hospital, and Department of Pediatrics, \\ Harvard Medical School, Boston, Massachusetts 02115
}

\begin{abstract}
To evaluate the pathophysiologic importance of renal nerves in regulating the renal vasomotor tone, we measured several parameters of renal cortical microcirculation before and after acute renal denervation (DNx) in the following three groups of anesthetized Munich-Wistar rats: (group 1) congestive heart failure after surgically induced myocardial infarction $(n=10)$, (group 2) acute extracellular fluid volume depletion after deprivation of drinking water for $48 \mathrm{~h}(n=8)$, and (group 3) sham or nontreated controls $(n=6)$. In the myocardial-infarcted rats, DNx led to a uniform increase in glomerular plasma flow rate of, on average, $36 \%$. Single nephron glomerular filtration rate of myocardialinfarcted rats also increased despite a reduction in glomerular capillary hydraulic pressure. These changes were associated with a fall in arteriolar resistances, particularly in the efferent arteriole. The glomerular capillary ultrafiltration coefficient rose in all but one myocardial-infarcted animal. A similar hemodynamic pattern was seen after DNx in water-deprived animals. In every water-deprived animal, glomerular plasma flow rate and single nephron GFR increased on average by 28 and 14\%, respectively. Again, afferent and efferent arteriolar resistances decreased significantly. Furthermore, the ultrafiltration coefficient increased uniformly and substantially with DNx.

To ascertain the potential importance of the interaction between the renal nerves and angiotensin $I I$ in these circumstances, we compared the renal cortical hemodynamics in additional groups of water-deprived rats (group 4) after DNx $(n=15)$, (group 5) during inhibition of angiotensin II with saralasin $(n=15)$, and (group 6) during treatment with both saralasin and DNx $(n=15)$. No appreciable difference was detected between group 4 vs. 6. In contrast, substantial differences were noted between group 5 vs. 6: on average, the glomerular plasma flow rate was $26 \%$ higher and the afferent and efferent arteriolar resistances $25 \%$ and $27 \%$ lower, respectively, in group 6.
\end{abstract}

Portions of these studies were presented at the annual meeting of the American Society of Nephrology, Washington, DC, 1984, and at the Annual Meeting of the Federations of American Societies for Experimental Biology, Washington, DC, 1985, and were published in abstract form (1984. Am. Soc. Nephrol. 17:134; and 1985. Clin. Res. 33:489A). Address correspondence to Dr. Kon, Laboratory of Renal Physiology. 1985

Received for publication 8 January 1985 and in revised form 12 July

J. Clin. Invest.

(C) The American Society for Clinical Investigation, Inc.

0021-9738/85/11/1913/08 $\$ 1.00$

Volume 76, November 1985, 1913-1920
These observations provide direct evidence to indicate pathophysiologic importance of renal nerves in the profound intrarenal circulatory adjustments in prerenal circulatory impairment. The vasoconstrictive effects of renal nerves appear to be mediated in part by their stimulatory influence on angiotensin II release and their direct constrictor actions on pre- and postglomerular vessels as well.

\section{Introduction}

It is well known that at normal base-line conditions, activation of renal nerves causes antidiuresis and antinatriuresis (1-4). Conversely, removal of the renal nerve influence by acute denervation of the kidney is associated with increased urine flow and sodium excretion $(5,6)$. These phenomena have been attributed by many investigators to reflect a direct influence of renal nerves on the tubule reabsorption processes. Micropuncture measurements in normal animals have shown that acute renal denervation led to a decrease in the fractional reabsorption of sodium and water by the proximal tubule (5-8). That renal nerves directly influence tubule transport is further supported by several whole kidney clearance studies in which acute denervation-induced diuresis and natriuresis in normal animals were not accompanied by changes in renal hemodynamics or the rate of glomerular filtration $(5,6)$. These observations have been taken to indicate that, in contrast to their significant influence on tubule transport, renal nerves contribute little to the vasomotor tone of normal animals under baseline physiologic conditions.

These conclusions, however, do not preclude the possibility that when the efferent neural tone is heightened above baseline level, it may profoundly influence renal circulatory dynamics. In fact, direct activation of renal nerves above baseline level induces an increase in renal vascular resistances proportional to the degree of nerve stimulation $(4,9-12)$. Recent studies localized the effects of renal nerve stimulation to the pre- and postglomerular arterioles, where they cause constriction, as well as reduction in glomerular capillary ultrafiltration coefficient $(4,13,14)$. These neural influences on renal hemodynamics are reminiscent of actions of many other vasoactive substances. For example, suppression of endogenous angiotensin II actions in normal animals by administration of specific angiotensin II inhibitors has repeatedly been shown to elicit minimal changes in renal hemodynamics and glomerular filtration rate $(15,16)$. At the same time, it is now well recognized that exogenous administration of angiotensin II is capable of causing profound vasoconstriction $(17,18)$. Moreover, in circumstances in which renin- 
angiotensin levels are elevated, such as chronic extracellular fluid $(E C F)^{1}$ volume depletion induced by restriction of salt intake, administration of an angiotensin II inhibitor markedly alters renal hemodynamics and glomerular filtration (19). Therefore, it appeared warranted to examine whether the profound effects of renal nerves on renal vasculature demonstrated by experimental electrical stimulation do, in fact, participate in pathophysiologic settings. Two conditions, congestive heart failure and acute ECF volume depletion, are characterized by marked renal vasoconstriction, including high afferent and efferent arteriolar resistances and depressed glomerular capillary ultrafiltration coefficient $(15,20)$. The sympathetic tone is believed to be markedly enhanced in both of these conditions (21-24). To determine the causal role of renal nerves under these circumstances, we removed the direct adrenergic influence of nerves by renal denervation and evaluated the renal microcirculatory indices before and after denervation. The possible intermediary role of angiotensin II was also explored by using an angiotensin II antagonist.

\section{Methods}

Treatment before micropuncture experiments. Studies were performed in adult male Munich-Wistar rats weighing 183-369 g. Group 1 ( $n$ $=10$ ) consisted of animals with congestive heart failure secondary to myocardial infarction (MI). Infarcts were surgically produced using the technique previously described (25). Briefly, under ether anesthesia, a left thoracotomy was performed and the heart exteriorized. The left coronary artery was ligated between the pulmonary outflow tract and the left auricle. In some animals, distal branches of the left and/or right coronary arteries were also cauterized. The heart was then returned into the chest and the thorax closed. The rats were allowed free access to tap water and standard rat chow. Micropuncture experiments were performed $\sim 4$ wk after surgery. Only rats having left ventricular end-diastolic pressure (LVEDP) $>15 \mathrm{mmHg}$ during the micropuncture experiments were included in group 1. Group $2(n=8)$ were normal rats deprived of water for $48 \mathrm{~h}$ before the experiment (acute water deprivation [AWD]). Group $3(n=6)$ included four sham-operated animals that underwent a thoracotomy and exteriorization of the heart and two nonoperated animals. Group 3 animals were maintained on standard rat chow and water ad libitum until the day of experiment. In addition to these three groups of animals, which underwent two-period studies described below, three more groups of water-deprived rats (groups 4-6) were prepared for a oneperiod micropuncture study in a fashion identical to that in group 2.

Treatment during micropuncture experiments. On the day of experiment, all animals were anesthetized with Inactin (Byk, Federal Republic of Germany; $100 \mathrm{mg} / \mathrm{kg}$, i.p.) and placed on a temperature-regulated micropuncture table. Each animal underwent a tracheostomy. In-dwelling polyethylene catheters were inserted into the right and left jugular veins for infusion of inulin and isoncotic rat plasma. A $0.2-\mathrm{ml}$ bolus of $10 \%$ inulin in $\mathrm{NaCl}$ was given, followed by a continuous infusion at the rate

1. Abbreviations used in this paper: AP, femoral arterial pressure; AWD, acute water deprivation; $C_{A}$, protein concentration in systemic plasma; $C_{E}$, protein concentration in efferent arteriolar plasma; ECF, extracellular fluid; Hct, blood hematocrit in femoral artery; $K_{f}$, glomerular capillary ultrafiltration coefficient; LVEDP, left ventricular end-diastolic pressure; $P_{E}$, hydraulic pressure in surface efferent arteriole; $P_{G C}$, hydraulic pressure in single glomerular capillary; $\mathrm{MI}$, myocardial infarction; $\mathrm{P}_{\mathrm{T}}$, hydraulic pressure in proximal tubule; $\Delta \mathrm{P}$, glomerular transcapillary hydraulic pressure difference $\left(=P_{G C}-P_{T}\right) ; Q_{\Lambda}$, glomerular plasma flow rate; $R_{\Lambda}$ and $R_{E}$, resistance to blood flow in afferent and efferent arteriole, respectively; SNFF, single nephron filtration fraction; SNGFR, single nephron glomerular filtration rate; $(\mathrm{TF} / \mathrm{P})_{\mathrm{ln}}$, proximal tubule fluid-toplasma inulin concentration ratio; $U_{\mathrm{Na}} \dot{\mathrm{V}}$, urinary sodium excretion rate; $\dot{\mathrm{V}}$, urine flow rate; $\dot{\mathrm{V}}_{\mathrm{TF}}$, tubule fluid flow rate; -, (over-bar) mean value. of $1.2 \mathrm{ml} / \mathrm{h}$. Plasma equal to $1 \%$ body weight in groups 1 and 3 , and $0.5-0.7 \%$ body weight in groups $2,4,5$, and 6 were infused, followed by infusion of $1.2 \mathrm{ml} / \mathrm{h}$ throughout the remainder of the experiment to replace the plasma volume lost during surgical preparation $(20,26)$. The left femoral artery was catheterized for periodic sampling of blood and recording of mean systemic arterial blood pressure $(\overline{\mathrm{AP}})$. $\overline{\mathrm{AP}}$ was monitored with an electronic transducer (model P-23Db [Statham Instruments Div., Gould Inc., Oxnard, CA]) connected to a direct writing recorder (model 2200 [Gould Inc.]). An in-dwelling left ventricular catheter was inserted through the right carotid artery and connected to a Millar micromanometer (PC-350, Millar Industries, Houston, TX), which was linked to the writing recorder.

The left kidney was exposed by ventral midline and subcostal incisions and suspended on a Lucite holder. Its surface was illuminated with a fiberoptic light source and bathed with $0.9 \% \mathrm{NaCl}$. All micropuncture measurements and collections were obtained from the left kidney. In each one of the animals from groups 1-3, base-line micropuncture measurements and specimen collections specified below were begun 90-120 min after induction of anesthesia. The base-line period was completed within $\mathbf{3 0}$ min. Renal denervation was then carried out as previously described $(5,7)$. The nerve bundles running parallel with the renal artery were severed. In addition, the renal artery was carefully stripped of its adventitia and swabbed with a $10 \%$ phenol solution, care being taken to protect the kidney and surrounding tissues. To ascertain the completeness of this denervation technique, we electrically stimulated the splanchnic nerve by placing it on a bipolar electrode connected to a Grass stimulator (model S44 [Grass Instrument Co., Quincy, MA]), set to deliver a squarewave signal for $0.5 \mathrm{~ms}$ at $5 \mathrm{~V}$ and $5-10 \mathrm{~Hz}$. It has previously been shown by us and others that nerve stimulation at this frequency range caused profound renal vasoconstriction, which is evidenced by blanching of the kidney surface if the renal nerve is intact $(4,13,14)$. In the rats undergoing denervation, micropuncture measurements were begun after a $45-60$ min equilibration period and completed within $\sim 30 \mathrm{~min}$.

In the AWD animals of groups 4-6, micropuncture measurements and collections were performed only once (one-period study). In designing the study for groups 4-6, it was felt necessary to perform experiments in a relatively large number of animals ( $~ 15$ in each group), since a wide animal-to-animal variability within each group might otherwise hinder meaningful statistical group-to-group comparison. Group 4 defines AWD animals that underwent denervation, and includes the second period of group 2. Micropuncture measurements were performed 90 120 min after denervation. In group $5(n=15)$ AWD animals, micropuncture was performed during infusion of saralasin $(0.3 \mathrm{mg} / \mathrm{kg} / \mathrm{h}$, i.v.), an angiotensin II antagonist. ${ }^{2}$ Saralasin was begun $40-120 \mathrm{~min}$ before measurements of cortical hemodynamics and continued throughout the experiment. Group $6(n=15)$ AWD animals underwent both saralasin treatment and renal denervation. Group 6 experiments include animals that were first denervated, then infused with saralasin (the same rats as group $4, n=6$ ), or treated vice versa (the same rats as group 5, $n=6$ ), or which underwent both treatments simultaneously (separate rats, $n=3$ ).

Micropuncture measurements. Micropuncture measurements and collections were carried out as follows. Timed (1-2 min) samples of fluid were collected from surface proximal tubules from each of two or three nephrons for determination of flow rate, inulin concentration, and calculation of tubule fluid-to-plasma inulin concentration ratio $\left([\mathrm{TF} / \mathrm{P}]_{\mathrm{ln}}\right)$, hence single nephron glomerular filtration rate (SNGFR). The rate of fluid collection was adjusted to maintain a column of polymer oil, three to four tubule diameters in length, in a constant position just distal to the site of puncture. Coincident with tubule fluid collection, femoral arterial blood samples were obtained for determination of hematocrit and plasma inulin concentration. Urine was collected from the right and

2. This dose of saralasin has previously been used by several investigators $(18,20,27)$ and has been shown to inhibit the microcirculatory changes induced by endogenous and exogenous angiotensin II. There exists the theoretical possibility, however, that in these experiments, angiotensin II may only be partially inhibited by saralasin. 
left kidneys for determination of flow rate $(\dot{V})$, renal sodium excretion rate $\left(\mathrm{U}_{\mathrm{Na}} \dot{\mathrm{V}}\right)$, and inulin for the glomerular filtration rate (GFR). For the urine collections, in-dwelling ureteral polyethylene catheters (PE-10) were used.

Hydraulic pressures were monitored in accessible surface structures with a continuous-recording servo-null micropipette transducer system (model 3 [Instrumentation for Physiology and Medicine, San Diego, CA]). Micropipettes with outer tip diameters of 1-2 $\mu \mathrm{m}$ containing $2.0 \mathrm{M} \mathrm{NaCl}$ were used. Hydraulic output from the servo-null system was coupled electronically to the recorder by means of a pressure transducer. Direct measurements of time-averaged hydraulic pressures were recorded in single capillaries of surface glomeruli $\left(\mathrm{P}_{\mathrm{GC}}\right)$, proximal tubules $\left(P_{T}\right)$, and efferent arterioles $\left(P_{E}\right)$. Protein concentrations of plasma entering $\left(C_{A}\right)$ and leaving $\left(C_{E}\right)$ glomerular capillaries were determined by analyzing femoral arterial and surface efferent arteriolar plasma, respectively (28). Protein content was analyzed by the fluorometric technique of Viets et al. (29). The oncotic pressure was calculated from the protein concentrations determined by the relationship previously described (30).

The volume of fluid collected from individual tubules was estimated from the length of the fluid column in a constant-bore capillary tube of known internal diameter. The concentration of inulin in tubule fluid was measured in duplicate by the microfluorescence method of Vurek and Pegram (31). Inulin concentrations in plasma were determined by the macroanthrone method of Führ et al. (32). The sodium concentration in the urine was determined by flame photometry.

Calculations. SNGFR was calculated by SNGFR $=(\mathrm{TF} / \mathrm{P})_{\mathrm{in}} \times \dot{\mathrm{V}}_{\mathrm{TF}}$, where $(T F / P)_{\text {In }}$ and $\dot{\mathrm{V}}_{\mathrm{TF}}$ refer to tubule fluid-to-plasma inulin concentration ratio and tubule fluid flow rate, respectively. Glomerular capillary ultrafiltration coefficient $\left(K_{\mathbf{f}}\right)$ and resistances of single afferent $\left(\mathbf{R}_{\mathbf{A}}\right)$ and efferent $\left(R_{E}\right)$ arterioles were calculated using equations described in detail elsewhere (30).

Paired $t$ test was used for period to period comparison within the same group. Analysis of variance was used to compare groups 4, 5, and 6. Statistical significance is defined as $P<0.05$. Significance for analysis of variance are given at levels of $P<0.05$ and $P<0.01$.

\section{Results}

Group 1 (MI rats). LVEDP of MI animals ranged from 15 to $30 \mathrm{mmHg}$, with a mean value of $21 \mathrm{mmHg}$. Other pertinent parameters of systemic and renal functions during the control period and after renal denervation are shown in Table I. When compared to the identically prepared MI rats in our previous experiments (15), the degree of impairment of cardiac performance in the current rats appears to be somewhat less, i.e., higher mean systemic arterial pressure (101 vs. $96 \mathrm{mmHg}$ ) and lower values for LVEDP ( 21 vs. $24 \mathrm{mmHg}$ ). Nevertheless, the renal microcirculatory pattern found in the present series of $\mathrm{MI}$ rats was qualitatively similar to that reported earlier (15). Thus, compared to normal control rats, MI rats were again characterized by high afferent and efferent arteriolar resistances and reduced ultrafiltration coefficient.

Comparing various measurements before and after dener-

Table I. Summary of Whole Body and Bilateral Kidney Function

\begin{tabular}{|c|c|c|c|c|c|c|c|c|c|}
\hline & \multirow[b]{2}{*}{ Body wt } & \multirow[b]{2}{*}{$\overline{\mathbf{A P}}$} & \multirow[b]{2}{*}{ Hct } & \multicolumn{2}{|l|}{$\dot{\mathbf{v}}$} & \multicolumn{2}{|l|}{$\mathrm{U}_{\mathrm{Na}_{\mathrm{V}}} \dot{\mathrm{V}}$} & \multicolumn{2}{|l|}{ GFR } \\
\hline & & & & $\mathbf{R}$ & $\mathbf{L}$ & $\mathbf{R}$ & $\mathbf{L}$ & $\mathbf{R}$ & $\mathbf{L}$ \\
\hline & $g$ & $m m H g$ & vol\% & $\mathrm{ml} / \mathrm{min}$ & $\mathrm{ml} / \mathrm{min}$ & $\mu e q / \min$ & $\mu e q / \min$ & $\mathrm{ml} / \mathrm{min}$ & $\mathrm{ml} / \mathrm{min}$ \\
\hline \multicolumn{10}{|l|}{ MI ( $n=10$ rats $)$} \\
\hline \multirow[t]{2}{*}{ Baseline } & 280 & 101 & 47 & 0.0064 & 0.0074 & 0.32 & 0.35 & 0.77 & 0.68 \\
\hline & \pm 14 & 4 & 1 & 0.0010 & 0.0011 & 0.05 & 0.07 & 0.09 & 0.07 \\
\hline Denervation & & 103 & 47 & 0.0098 & 0.0194 & 0.65 & 1.32 & 0.76 & 0.88 \\
\hline (left kidney) & & 4 & 1 & 0.0021 & 0.0034 & 0.13 & 0.34 & 0.07 & 0.09 \\
\hline$P$ value* & & NS & NS & NS & $<0.05$ & NS & $<0.01$ & NS & $<0.05$ \\
\hline$P$ value $\ddagger$ & & NS & NS & NS & NS & NS & NS & NS & NS \\
\hline \multicolumn{10}{|l|}{$\operatorname{AWD}(n=8$ rats $)$} \\
\hline \multirow[t]{2}{*}{ Baseline } & 247 & 106 & 56 & 0.0036 & 0.0040 & 0.14 & 0.14 & 0.65 & 0.62 \\
\hline & \pm 11 & 3 & 1 & 0.0005 & 0.0005 & 0.04 & 0.05 & 0.07 & 0.11 \\
\hline Denervation & & 103 & 55 & 0.0042 & 0.0052 & 0.23 & 0.27 & 0.62 & 0.68 \\
\hline (left kidney) & & 3 & 1 & 0.0006 & 0.0004 & 0.09 & 0.06 & 0.12 & 0.11 \\
\hline$P$ value* & & NS & $<0.025$ & NS & $<0.05$ & NS & $<0.05$ & NS & $<0.05$ \\
\hline$P$ value & & NS & NS & NS & $<0.05$ & NS & NS & NS & NS \\
\hline \multicolumn{10}{|l|}{ CONT ( $n=6$ rats) } \\
\hline \multirow[t]{2}{*}{ Baseline } & 290 & 115 & 48 & 0.0086 & 0.0086 & 0.44 & 0.50 & 0.86 & 0.91 \\
\hline & \pm 18 & 4 & 1 & 0.0009 & 0.0007 & 0.05 & 0.12 & 0.30 & 0.16 \\
\hline Denervation & & 115 & 48 & 0.0108 & 0.0125 & 0.53 & 0.80 & 0.97 & 0.87 \\
\hline (left kidney) & & 4 & 1 & 0.0024 & 0.0015 & 0.13 & 0.05 & 0.07 & 0.12 \\
\hline$P$ value* & & NS & NS & NS & $<0.05$ & NS & $<0.025$ & NS & NS \\
\hline
\end{tabular}

Values are expressed as mean \pm SE. CONT, control. R, right kidney. L, left kidney. NS denotes $P>0.05 .{ }^{*} t$ tests were performed between the baseline and denervation in the same group. Statistical comparison was also performed for denervation-induced changes between MI vs. CONT (‡) and AWD vs. CONT (§). 
Table II. Summary of Parameters for Cortical Microcirculation of the Left Kidney

\begin{tabular}{|c|c|c|c|c|c|c|c|c|c|c|}
\hline & SNGFR & $P_{o c}$ & $\mathbf{P}_{\mathbf{T}}$ & $\overline{\Delta \mathbf{P}}$ & $\mathrm{C}_{\mathrm{A}}$ & $\mathbf{Q}_{n}$ & SNFF & $\mathbf{R}_{\mathbf{A}}$ & $\mathbf{R}_{\mathbf{E}}$ & $K_{f}$ \\
\hline & $n l / \min$ & $m m H g$ & $\mathrm{mmHg}$ & $m m H g$ & g/dl & $n l / m i n$ & & $\times 10^{10} \mathrm{dym}$ & $\mathrm{cm}^{-\mathrm{s}}$ & $n l /(s \cdot m m H g)$ \\
\hline \multicolumn{11}{|l|}{$\begin{array}{c}\text { MI }(n=10 \text { rats): } \\
\text { Group } 1\end{array}$} \\
\hline \multirow[t]{2}{*}{ Baseline } & 26.6 & 52.6 & 13.0 & 39.9 & 5.9 & 92.0 & 0.31 & 2.61 & 2.19 & 0.0414 \\
\hline & \pm 2.3 & 0.7 & 0.7 & 1.1 & 0.1 & 12.8 & 0.02 & 0.43 & 0.35 & 0.0045 \\
\hline Denervation & 30.8 & 49.0 & 12.8 & 36.3 & 6.1 & 122.7 & 0.27 & 0.29 & 1.41 & 0.0640 \\
\hline (left kidney) & \pm 2.1 & 1.0 & 0.4 & 0.8 & 0.1 & 18.4 & 0.02 & 0.37 & 0.15 & 0.0103 \\
\hline$P$ value* & $<0.01$ & $<0.01$ & NS & $<0.01$ & $<0.025$ & $<0.025$ & NS & NS & $<0.01$ & NS \\
\hline$P$ value $\neq$ & $<0.01$ & NS & NS & $<0.05$ & $<0.05$ & $<0.01$ & NS & NS & $<0.01$ & NS \\
\hline \multicolumn{11}{|l|}{$\begin{array}{c}\text { AWD ( } n=8 \text { rats): } \\
\text { Group } 2\end{array}$} \\
\hline \multirow[t]{2}{*}{ Baseline } & 27.8 & 56.7 & 11.9 & 44.8 & 6.7 & 80.8 & 0.36 & 2.46 & 2.15 & 0.0511 \\
\hline & \pm 3.3 & 2.1 & 1.0 & 1.8 & 0.1 & 12.3 & 0.02 & 0.35 & 0.37 & 0.0073 \\
\hline Denervation & 31.2 & 51.2 & 13.3 & 38.2 & 6.5 & 107.6 & 0.30 & 1.96 & 1.40 & 0.0723 \\
\hline (left kidney) & \pm 3.3 & 1.6 & 0.9 & 1.6 & 0.2 & 15.9 & 0.02 & 0.26 & 0.15 & 0.0083 \\
\hline$P$ value $*$ & $<0.025$ & $<0.005$ & NS & $<0.001$ & $<0.05$ & $<0.005$ & $<0.005$ & $<0.05$ & $<0.025$ & $<0.001$ \\
\hline$P$ value§ & $<0.05$ & $<0.01$ & NS & $<0.01$ & NS & $<0.01$ & $<0.05$ & $<0.05$ & $<0.05$ & NS \\
\hline \multicolumn{11}{|l|}{$\begin{array}{c}\text { CONT ( } n=6 \text { rats): } \\
\text { Group } 3\end{array}$} \\
\hline \multirow[t]{2}{*}{ Baseline } & 41.4 & 50.9 & 12.3 & 38.5 & 5.7 & 135.9 & 0.31 & 2.00 & 1.21 & 0.0650 \\
\hline & \pm 2.0 & 1.5 & 1.2 & 2.0 & 0.2 & 12.4 & 0.02 & 0.29 & 0.08 & 0.0118 \\
\hline Denervation & 38.9 & 50.1 & 12.0 & 38.1 & 5.7 & 132.6 & 0.30 & 2.20 & 1.35 & 0.0712 \\
\hline (left kidney) & \pm 2.1 & 1.8 & 1.0 & 2.1 & 0.2 & 14.0 & 0.02 & 0.31 & 0.29 & 0.0187 \\
\hline$P$ value ${ }^{*}$ & NS & NS & NS & NS & NS & NS & NS & NS & NS & NS \\
\hline
\end{tabular}

Values expressed as mean \pm SE. CONT, control rats. NS denotes $P>0.05$. Statistical comparison performed between the initial and second periods in the same rat $\left(^{*}\right)$ as well as for changes induced by denervation between MI and CONT ( $)$ and AWD and CONT (§) rats. Values for $\Pi_{E} / \overline{\Delta P}$ were found to be $<0.95$ (unique value for $K_{f}$ ) in six MI rats in the initial period and six after denervation; three AWD rats in the initial period and two after denervation were calculated to have unique $K_{\mathrm{f}}$ values; three CONT rats in the initial period and six after denervation were calculated to have unique $K_{f}$ values. These unique values of $K_{f}$ were pooled with minimum values obtained under equilibrium conditions in calculating the means.

vation revealed that left renal denervation did not affect $\overline{\mathrm{AP}}$, which remained essentially unchanged, $101 \pm 4$ vs. $103 \pm 4 \mathrm{mmHg}$. The blood hemocrit in femoral artery (Hct) also remained unchanged at $47 \pm 1 \mathrm{vol} \%$ in both periods. Although the rate of urine flow from the intact right kidney did not significantly change with left renal denervation, urine flow from the left kidney more than doubled, from an average of $0.0074 \pm 0.0011$ to $0.0194 \pm 0.0034 \mathrm{ml} / \mathrm{min}$. Similarly, sodium excretion increased substantially only in the left kidney, average of $0.35 \pm 0.07$ vs. $1.32 \pm 0.34 \mu \mathrm{eq} / \mathrm{min} .^{3}$ Whole kidney GFR $(n=8)$ in the right kidney was not affected by left renal denervation, $0.77 \pm 0.09$ vs.

3. Ipsilateral natriuresis has been shown to be accompanied by contralateral antinatriuresis, termed, renorenal reflex $(10,32)$. This phenomenon was not observed in our experiments. We hypothesize that the already heightened renal nerve tone in the pathophysiologic conditions of $\mathrm{MI}$ and AWD may not be responsive to further activation imposed by contralateral denervation. Our control rats (group 3) also differed from those previously described in that the previous studies described volume expanded animals undergoing sodium pentobarbital anesthesia, while the animals in the present experiments were euvolemic and were anesthetized with Inactin. These differences may explain the disparate findings.
$0.76 \pm 0.07 \mathrm{ml} / \mathrm{min}$, whereas denervation led to a GFR increase in the left kidney, on average from $0.68 \pm 0.07$ to $0.88 \pm 0.09 \mathrm{ml}$ / $\min (P<0.05)$.

The renal cortical microcirculatory parameters before and after denervation are shown in Table II. SNGFR increased on average from $26.6 \pm 2.3$ to $30.8 \pm 2.1 \mathrm{nl} / \mathrm{min}$. This increase reflects the increased SNGFR in eight animals and essentially unchanged SNGFR in two rats. This denervation-induced increase in SNGFR contrasted the absence of change in SNGFR level after renal denervation of normal rats. The $\overline{\mathrm{P}}_{\mathrm{GC}}$ of $\mathrm{MI}$ rats fell slightly with denervation, from a mean of $52.6 \pm 0.7$ to $49.0 \pm 1.0 \mathrm{mmHg}$. The $P_{\mathrm{T}}$ remained virtually unchanged at $13.0 \pm 0.7$ vs. $12.8 \pm 0.4$ $\mathrm{mmHg}$. Therefore, the mean glomerular transcapillary hydraulic pressure difference, $\overline{\Delta \mathrm{P}}$, was lower in the second period, a mean of $39.9 \pm 1.1 \mathrm{mmHg}$ fell to $36.3 \pm 0.8 \mathrm{mmHg}$. The $C_{A}$ increased slightly in the second period from $5.9 \pm 0.1$ to $6.1 \pm 0.1 \mathrm{~g} / \mathrm{dl}$. Denervation caused a uniform increase in the glomerular plasma flow rate, $Q_{A}$, which rose on average from $92.0 \pm 12.8$ to $122.7 \pm 18.4 \mathrm{nl} / \mathrm{min}$. This increase in plasma flow rate was associated with a fall in arteriolar resistances, particularly in the efferent arteriole, as shown in Table II. Lastly, the $K_{\mathrm{f}}$ rose from 
a mean of $0.0414 \pm 0.0045$ to $0.0640 \pm 0.0103 \mathrm{nl} /(\mathrm{s} \cdot \mathrm{mmHg})$. This numeric rise in $K_{\mathrm{f}}$ represents the direction of change in all but one animal; the change in the mean value, however, was just short of reaching statistical significance by $t$ test $(0.05<P$ $<0.10$ ).

Group 2 (water-deprived animals). The parameters for systemic and renal microcirculatory dynamics of water-deprived rats are also shown in Tables I and II. $\overline{\mathrm{AP}}$ averaged $106 \pm 3 \mathrm{mmHg}$ before and $103 \pm 3 \mathrm{mmHg}$ after renal denervation. The Hct fell by $1 \mathrm{vol} \%$, from $56 \pm 1$ to $55 \pm 1$. Urine volume and sodium excretion rose significantly only in the denervated left kidney, as shown in Table I. Whole kidney GFR $(n=6)$ in the intact right kidney was $0.65 \pm 0.07 \mathrm{ml} / \mathrm{min}$ before and $0.62 \pm 0.12$ $\mathrm{ml} / \mathrm{min}$ after left denervation (NS), while the left kidney increased slightly, but significantly, from $0.62 \pm 0.11$ to $0.68 \pm 0.11$ $\mathrm{ml} / \mathrm{min}$ after denervation $(P<0.05)$. As in the rats with $\mathrm{MI}$, SNGFR rose slightly, from an average of $27.8 \pm 3.3$ to $31.2 \pm 3.3$ $\mathrm{nl} / \mathrm{min}$ (Table II). $\overline{\mathrm{P}}_{\mathrm{GC}}$ fell in every animal, averaging $56.7 \pm 2.1$ $\mathrm{mmHg}$ during the base-line period and $51.2 \pm 1.6 \mathrm{mmHg}$ after denervation. Together with the trend toward higher value of $P_{T}$ following denervation, $\overline{\Delta \mathrm{P}}$ was markedly lower in the second study period, mean $44.8 \pm 1.8$ vs. $38.2 \pm 1.6 \mathrm{mmHg}$. Systemic plasma protein concentration decreased slightly from an average of $6.7 \pm 0.1$ to $6.5 \pm 0.2 \mathrm{~g} / \mathrm{dl}$. $\mathrm{Q}_{\mathrm{A}}$ increased in every animal, averaging $80.8 \pm 12.3 \mathrm{nl} / \mathrm{min}$ with renal nerves intact and $107.6 \pm 15.9 \mathrm{nl} / \mathrm{min}$ after denervation. Both $R_{A}$ and $R_{E}$ fell significantly, as shown in Table II. The relatively greater increase in $Q_{A}$ than SNGFR in this group of animals is reflected by the fall in single nephron filtration fraction, a mean of $0.36 \pm 0.02$ fell to $0.30 \pm 0.02$. Finally, the value for $K_{\mathrm{f}}$ also increased significantly with renal denervation, i.e., from $0.0511 \pm 0.0073$ to $0.0723 \pm 0.0083 \mathrm{nl} /(\mathrm{s} \cdot \mathrm{mmHg})$.

Group 3 (normal control). To test whether the effects of renal denervation seen in Groups 1 and 2 animals were specific to the experimental conditions of these animals, we subjected a third group of normal Munich-Wistar rats to micropuncture study. Blood pressure and Hct were again not affected by denervation. As can be seen in Table I, renal denervation increased urine flow in the left kidney, from an average of $0.0086 \pm 0.0007$ to $0.0125 \pm 0.0015 \mathrm{ml} / \mathrm{min}$. The magnitude of this increase was larger in these euvolemic animals than the postdenervation increase in urine volume observed in AWD rats. Sodium excretion also rose only in the left kidney, mean $0.50 \pm 0.12$ vs. $0.80 \pm 0.05$ $\mu \mathrm{eq} / \mathrm{min}$. Whole kidney GFR was not affected by left renal denervation in either kidney $0.86 \pm 0.30$ vs. $0.97 \pm 0.07 \mathrm{ml} / \mathrm{min}$ on the right and $0.91 \pm 0.16$ vs. $0.87 \pm 0.12 \mathrm{ml} / \mathrm{min}$ on the left. A similar pattern has been observed by many previous investigators (5-8). By contrast, due to the subtle and directionally dissimilar effects of renal denervation on hemodynamics among the animals studied, statistical significance was not reached in any of the microcirculatory parameters described in Table II. These findings echo previous micropuncture observations following renal denervation (7).

Groups 4-6. To examine the potential interaction between renal nerves and angiotensin II in renal cortical microcirculation, we studied three groups of water-deprived rats. The results of renal denervation alone, treatment with saralasin alone, or both of these maneuvers are shown on Table III. Comparison between group 4 (denervation alone) and group 6 (both saralasin treatment and denervation) revealed that the systemic blood pressure was lower following simultaneous saralasin treatment and denervation than denervation alone $(98 \pm 3$ vs. $107 \pm 3 \mathrm{mmHg})$. Similarly, values for $\overline{\mathrm{P}}_{\mathrm{GC}}$ were lower in group 6 than group 4 $(48.2 \pm 1.1$ vs. $52.8 \pm 1.2 \mathrm{mmHg})$. Values for $\mathrm{P}_{\mathrm{T}}$ were also slightly but significantly lower in group 6 than group $4 . \overline{\Delta \mathrm{P}}$, although numerically lower in the saralasin- plus denervation-treated rats than denervation alone, was not significantly different. Except for the slight decrease in $C_{A}$, statistical significance was not reached in any of the other parameters of microcirculatory dynamics between these two groups.

The effects of administering saralasin to acutely water-deprived animals has recently been described in detail (20) and the results are comparable, including the tendency toward lower $R_{A}, R_{E}$, and higher $Q_{A}$ (group 2 baseline vs. group 5), although these comparisons did not reach statistical significance in the present study. In the current study, we compared the treatment

Table III. Summary of Systemic and Renal Microcirculatory (Left) Hemodynamics in Acutely Water-deprived Rats Undergoing Either Left Renal Denervation, Saralasin, or Both Treatments

\begin{tabular}{|c|c|c|c|c|c|c|c|c|c|c|c|c|}
\hline & $\overline{\mathrm{AP}}$ & SNGFR & $\overline{\mathrm{P}}_{\mathrm{OC}}$ & $\mathbf{P}_{\mathbf{T}}$ & $\overline{\Delta \mathrm{P}}$ & $\mathrm{C}_{\mathrm{A}}$ & Het & $Q_{A}$ & SNFF & $\mathbf{R}_{\mathbf{A}}$ & $\mathbf{R}_{\mathbf{E}}$ & $K_{f}$ \\
\hline & $m m H g$ & $\mathrm{nl} / \mathrm{min}$ & $m m H g$ & $m m H g$ & $m m H g$ & $g / d l$ & vol\% & $n l / m i n$ & & \multicolumn{2}{|c|}{$\times 10^{10} \mathrm{dyn} \cdot \mathrm{s} \cdot \mathrm{cm}^{-\mathrm{s}}$} & $n l /(s \cdot m m H g)$ \\
\hline Group 4 AWD & 107 & 32.0 & 52.8 & 13.6 & 39.2 & 6.5 & 54 & 117.5 & 0.29 & 1.87 & 1.41 & 0.0678 \\
\hline $\begin{array}{l}\text { denervation } \\
(n=15)\end{array}$ & \pm 3 & 2.6 & 1.2 & 0.6 & 1.2 & 0.1 & 1 & 11.4 & 0.01 & 0.19 & 0.16 & 0.0070 \\
\hline Group 5 AWD & 104 & 28.1 & 49.8 & 12.1 & 37.8 & 6.6 & 53 & 99.2 & 0.30 & 2.18 & 1.47 & 0.0788 \\
\hline $\operatorname{Sar}(n=15)$ & \pm 3 & 1.2 & 1.0 & 0.8 & 1.0 & 0.1 & 1 & 6.3 & 0.02 & 0.19 & 0.15 & 0.0120 \\
\hline Group 6 AWD & 98 & 29.2 & 48.2 & 12.1 & 36.1 & 6.2 & 52 & 124.9 & 0.25 & 1.64 & 1.08 & 0.0593 \\
\hline $\begin{array}{l}\text { Sar }+ \text { denervation } \\
(n=15)\end{array}$ & \pm 3 & 1.3 & 1.1 & 0.8 & 1.0 & 0.1 & 1 & 9.1 & 0.02 & 0.13 & 0.11 & 0.0079 \\
\hline$P$ value $\Phi$ & $<0.05$ & NS & $<0.01$ & $<0.01$ & NS & $<0.05$ & NS & NS & NS & NS & NS & NS \\
\hline$P$ value $\Psi$ & NS & NS & NS & NS & NS & $<0.01$ & NS & $<0.05$ & NS & $<0.05$ & $<0.05$ & NS \\
\hline
\end{tabular}

Values expressed as mean \pm SE. Sar, saralasin. NS denotes $P>0.05$. Statistical comparison performed between denervation vs. Sar + denervation $(\Phi)$ also for Sar vs. Sar + denervation $(\Psi)$. Values for $\Pi_{\mathrm{E}} / \overline{\Delta \mathrm{P}}$ were found to be $<0.95$ (unique value for $K_{f}$ ) in nine denervated rats; five Sar rats; and $11 \mathrm{Sar}+$ denervated rats. These unique values were pooled with minimum values obtained under equilibrium conditions in calculating the means. 
with saralasin alone (group 5) with the effects produced by saralasin and denervation together (group 6). Systemic blood pressure tended to be lower in group 6 than group 5 , as shown in Table III. $\overline{\mathrm{P}}_{\mathrm{GC}}$ and $\overline{\Delta \mathrm{P}}$ were not different between these two groups. $C_{A}$ was somewhat higher in group 5 than group 6. Glomerular plasma flow was significantly higher in animals treated with both saralasin and denervation than those with saralasin treatment alone $(124.9 \pm 9.1$ vs. $99.2 \pm 6.3 \mathrm{nl} / \mathrm{min}, P<0.05)$. This higher value for $Q_{A}$ in group 6 was associated with a significantly lower level of $\mathbf{R}_{\mathbf{A}}$ in this group, as shown in Table III. Similarly, $R_{E}$ was lower in the saralasin- and DNx-treated animals than those with only saralasin treatment $(P<0.05)$ (Table III).

\section{Discussion}

Although urine flow and sodium excretion increased in the denervated left kidney in normal rats, denervation failed to change any of the parameters of renal cortical microcirculation in these control animals. These findings are in good agreement with previously reported micropuncture studies from other laboratories (5-8). In contrast, in the two experimental conditions studied, MI and AWD, denervation caused an amelioration of renal vasoconstriction, as evidenced by the significant increase in whole kidney and SNGFR, and $Q_{A}$. The cardiac performance of the currently studied animals appears to be less compromised than those previously reported (15), i.e., higher $\overline{\mathrm{AP}}$ and lower LVEDP. It is conceivable that with a more severe degree of heart failure, with more profound hypoperfusion of the renal cortex, the degree of vasodilation after denervation would be even greater.

In MI rats, changes in circulatory dynamics included a decrease in arteriolar resistances, particularly in $R_{E}$, on average by $30 \%$ of its base-line value. This was accompanied by a slight but uniform fall in the glomerular capillary hydraulic pressure and a marked increase in $Q_{A}$, which rose on average by $36 \%$ with denervation. Although the numerical increase in $K_{\mathrm{f}}$ was short of reaching statistical significance, the individual $K_{\mathrm{f}}$ values increased in all but one MI animal.

Hypoperfusion of renal cortical microcirculation in acute ECF volume depletion also appears to be attributable to the profound tonic influence of renal nerves on renal vasculature. As described in the Results section, denervation in water-deprived animals caused a uniform increase in $Q_{A}$. In these experiments, diminution of vasoconstriction was evidenced by the marked decreases in both afferent and efferent arterioles, and a uniform rise in the ultrafiltration coefficient. In association with these changes, a mild increase in SNGFR was seen after denervation.

The denervation-induced pattern of renal cortical microcirculation is qualitatively opposite to the changes seen in our previous study of stimulation of renal nerves in normal animals (4). That is, contrasting the amelioration of vasoconstriction that occurred after removal of renal nerves, we previously observed that electrical stimulation of renal nerves causes profound vasoconstriction. In response to moderately high frequency stimulation, $Q_{A}$ fell by $\sim 40 \%$. This reduction in plasma flow was accompanied by a marked increase in both $R_{A}$ and $R_{E}$. The glomerular capillary ultrafiltration coefficient also fell, on average by some $70 \%$ with nerve stimulation. These changes were sufficient to cause a reduction in SNGFR by $>50 \%$. As discussed above, in the current study of $\mathrm{MI}$ and water-deprived rats, di- rectionally opposite changes occurred in virtually all of these microcirculatory parameters after renal denervation. The findings of these and our previous studies are strengthened by numerous observations of adrenergic innervation of various vascular structures, including afferent and efferent arterioles and glomerular mesangium (34-38). ${ }^{4}$

It is believed that the sympathetic tone is enhanced in both acute ECF volume depletion and congestive heart failure, presumably through mechanisms involving activation and/or attenuation of baroreceptor systems (21-24). The enhanced sympathetic tone under these circumstances is believed to contribute to improved cardiac performance by increasing the heart rate and myocardial contractility, thereby sustaining perfusion to vital organs (39). It has been experimentally demonstrated that the antidiuresis and antinatriuresis induced by constriction of the thoracic vena cava or tricuspid insufficiency in dogs was abolished by pretreatment with systemic or intrarenally administered adrenergic blockers (40-43) or, as in the present study, surgical denervation (43-45). In some of these studies, whole kidney plasma flow rate, estimated by renal clearance of para-aminohippuric acid, was found to change to a relatively small and variable degree after the adrenergic inhibition $(40,41)$. By measuring pressures and flows in renal cortical microcirculation in MI and water-deprived animals, our study has provided direct evidence to indicate that renal nerves contribute substantially to the enhanced vasomotor tone and hypoperfusion of renal cortical circulation in some circumstances.

There is accumulating evidence of interaction between renal nerves and other vasoactive substances (43-51). The relationship between renal nerves and the renin angiotensin system, in particular, has generated intense interest. It has been shown that activation of renal nerves increased renal release of renin and generation of angiotensin II $(46,47)$. Pelayo et al. (13) recently showed that treatment of rats with angiotensin II inhibitors partially prevented reduction of SNGFR and $Q_{A}$ during mild electrical stimulation of renal nerves. It was speculated that the tonic influences of renal nerves on cortical microcirculation are, in part, mediated by enhanced renal renin release and angiotensin II action. In our study, therefore, an additional effort was made to examine the potential intermediary role of angiotensin II in the profound hemodynamic effects of renal nerves demonstrated in groups 1-3.

Intergroup comparison between denervation alone (group 4) vs. concurrent treatment with saralasin and denervation (group 6) revealed that inhibition of angiotensin II in a denervated kidney does not elicit further vasodilative response in cortical microcirculation (Table III) and indicates that the vasoconstrictive effects of angiotensin II on renal microcirculation are virtually entirely channeled through activation of renal nerves. On the other hand, when renal denervation was superimposed on angiotensin II antagonism, further renal vasodilatation was observed. Thus, in addition to their actions through enhanced angiotensin II, renal nerves appear to exert vasoconstrictor effects directly on the cortical microcirculation as evidenced by lower values for both afferent and efferent arteriolar vascular resistances measured in group 6 when compared with group 5. Fig. 1 summarizes our observations by considering four biological processes

4. In view of the fact that activation of nerves identified as sympathetic and adrenergic elicits a constrictor response in the renal vasculature, we have interchangeably used the terms sympathetic and adrenergic throughout the text. 


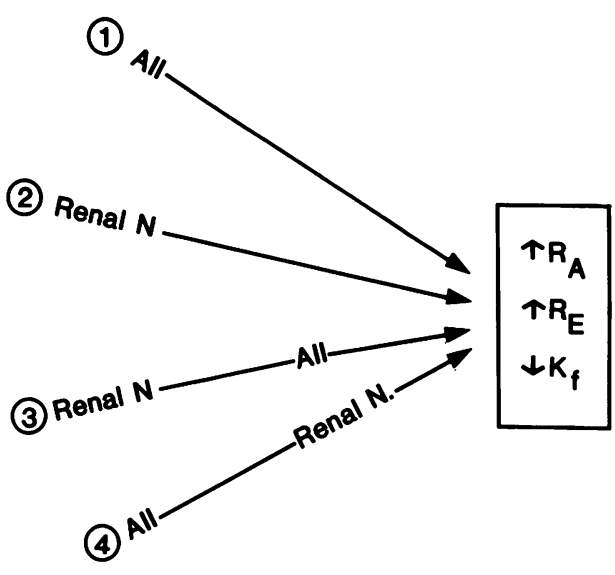

Figure 1. Summary of the four biological processes through which angiotensin II (AII) and renal nerves (Renal $N$ ) may contribute to high afferent $\left(\mathbf{R}_{\mathbf{A}}\right)$ and efferent $\left(\mathbf{R}_{\mathbf{E}}\right)$ arteriolar resistances in acute ECF volume depletion.

that may contribute to the vasoconstriction characteristic of AWD, namely increased arteriolar resistances and decreased glomerular capillary ultrafiltration coefficient. AII and renal nerves may act independently as renal constrictors, as indicated by arrows 1 and 2 in Fig. 1 . In addition, enhanced renal nerve activity may exert its constrictor actions through augmentation of intrarenal AII release, as discussed above (Fig. 1, arrow 3). Finally, high intrarenal levels of AII may facilitate local release or delay in uptake of norepinephrine by nerve endings, thereby causing the renal constriction response, as indicated by arrow 4 in Fig. $1(52,53)$. The absence of saralasin effects in previously denervated kidneys speaks against a significant contribution of the first process, that is direct actions of AII. Additional vasodilation following denervation in previously saralasin-treated animals supports process 2 , that is, direct vasoconstrictor action of renal nerves. Although this vasodilatory effect is not expected to occur through processes 3 and 4 (which have already been suppressed with saralasin), our previous observations that saralasin treatment in AWD rats with intact renal nerves causes renal vasodilation support these two possibilities (20).

Although the interactions between adrenergic and renin-angiotensin systems were examined only in AWD, it seems reasonable to speculate that this relationship also prevails in congestive heart failure. Supporting this notion are our recent findings that administration of teprotide, an angiotensin I converting enzyme inhibitor, led to hemodynamic alterations in renal cortical microcirculation that were similar to those following denervation in the present study (15). Demonstration of the important hemodynamic influences of renal nerve activation in the two experimental models of prerenal circulatory impairment suggests future studies to delineate the mechanisms of renal nerve activation.

\section{Acknowledgments}

The authors are grateful to Ms. Janet Stanley for her expert secretarial assistance.

This work was supported by U. S. Public Health Service grants AM34080 and AM-34792 and grant-in-aid from American Heart Association. Dr. Kon is a recipient of the American Heart Association Clinician Scientist Award.

\section{References}

1. Bello-Reuss, E., D. L. Trevino, and C. W. Gottschalk. 1976. Effect of renal sympathetic nerve stimulation on proximal water and sodium reabsorption. J. Clin. Invest. 57:1104-1107.

2. Zambraski, E. J., and G. F. DiBona. 1976. Angiotensin II in antidiuresis of low-level renal nerve stimulation. Am. J. Physiol. 231:11051110.

3. Slick, G. L., A. J. Aguilera, E. J. Zambraski, G. F. DiBona, and G. L. Kaloyanides. 1975. Renal neuroadrenergic transmission. Am. J. Physiol. 229:60-65.

4. Kon, V., and I. Ichikawa. 1983. Effector loci for renal nerve control of cortical microcirculation. Am. J. Physiol. 245:F545-F553.

5. Bello-Reuss, E., R. E. Colindres, E. Pastoriza-Muñoz, R. A. Mueller, and C. W. Gottschalk. 1975. Effects of acute unilateral denervation in the rat. J. Clin. Invest. 56:208-217.

6. Bello-Reuss, E., E. Pastoriza-Muñoz, and R. E. Colindres. 1977. Acute unilateral renal denervation in rats with extracellular volume expansion. Am. J. Physiol. 232:F26-F32.

7. Pelayo, J. C., M. G. Ziegler, P. A. Jose, and R. C. Blantz. 1983. Renal denervation in the rat: analysis of glomerular and proximal tubular function. Am. J. Physiol. 244(Renal Fluid Electrolyte Physiology 13): F70-F77.

8. Takacs, L., P. Bencsath, and L. Szalay. 1978. Decreased proximal tubular transport capacity after renal sympathectomy. Proc. Int. Congr. Nephrol. 8:553-558.

9. Block, M. A., K. G. Wakim, and F. C. Mann. 1952. Renal function during stimulation of renal nerves. Am. J. Physiol. 169:670-677.

10. DiBona, G. G., and L. L. Rios. 1980. Renal nerves in compensatory renal response to contralateral renal denervation. Am. J. Physiol. 238:F26-F30.

11. Johns, E. J., B. A. Lewis, and B. Singer. 1976. The sodium retaining effect of renal nerve activity in the cat: the role of angiotensin formation. Clin. Sci. 51:93-102.

12. DiSalvo, J., and C. Fell. 1971. Changes in blood flow during renal nerve stimulation. Proc. Soc. Exp. Biol. Med. 136:150-153.

13. Pelayo, J. C., M. G. Ziegler, and R. C. Blantz. 1984. Angiotensin II in adrenergic-induced alterations in glomerular hemodynamics. $\mathrm{Am}$. J. Physiol. 247:F799-F807.

14. Hermansson, K., M. Larson, Ö. Källskog, and M. Wolgast. 1981. Influence of renal nerve activity on arteriolar resistance, ultrafiltration dynamics and fluid reabsorption. Pfluegers Arch. 389:85-90.

15. Ichikawa, I., J. M. Pfeffer, M. A. Pfeffer, T. H. Hostetter, and B. M. Brenner. 1984. Role of angiotensin II in the altered renal function of congestive heart failure. Circ. Res. 55:669-675.

16. Ichikawa, I., R. A. Ferrone, K. L. Duchin, M. Manning, V. J. Dzau, and B. M. Brenner. 1983. Relative contribution of vasopressin and angiotensin II to the altered renal microcirculatory dynamics in twokidney Goldblatt hypertension. Circ. Res. 53:592-602.

17. Myers, B. D., W. E. Deen, and B. M. Brenner. 1975. Effects of norepinephrine and angiotensin II on the determinants of glomerular ultrafiltration and proximal tubule fluid reabsorption in the rat. Circ. Res. 37:101-110.

18. Blantz, R. C., K. S. Konnen, and B. J. Tucker. 1976. Angiotensin II effects upon the glomerular microcirculation and ultrafiltration coefficient of the rat. J. Clin. Invest. 57:419-434.

19. Steiner, R. W., B. J. Tucker, and R. C. Blantz. 1979. Glomerular hemodynamics in rats with chronic sodium depletion. J. Clin. Invest. 64:503-512.

20. Yared, A., V. Kon, and I. Ichikawa. 1985. Mechanism of preservation of glomerular perfusion and filtration during acute extracellular fluid volume depletion. Importance of intrarenal vasopressin-prostaglandin interaction for protecting kidneys from constrictor action of vasopressin. J. Clin. Invest. 75(5):1477-1487.

21. Braunwald, E. 1970. The sympathetic nervous system in heart failure. Hosp. Pract. 5(12):31-39. 
22. Gaffney, T. E., and E. Braunwald. 1963. Importance of the andrenergic nervous system in the support of circulatory function in patients with congestive heart failure. Am. J. Med. 34:320-324.

23. DiBona, G. F., and L. L. Sawin. 1983. Renal nerves in renal adaptation to dietary sodium restriction. Am. J. Physiol. 245(Renal Fluid Electrolyte Physiology 14):F322-F328.

24. DiBona, G. F., and L. L. Sawin. 1985. Renal nerve activity in conscious rats during volume expansion and depletion. Am. J. Physiol. 248(Renal Fluid Electrolyte Physiology 17):F15-F23.

25. Pfeffer, M. A., J. M. Pfeffer, M. C. Fishbein, P. J. Fletcher, J. Spadara, R. A. Kloner, and E. Braunwald. 1979. Myocardial infarct size and ventricular function in rats. Circ. Res. 44:503-512.

26. Ichikawa, I., D. A. Maddox, M. G. Cogan, and B. M. Brenner. 1978. Dynamics of glomerular ultrafiltration in euvolemic Munich-Wistar rats. Renal Physiol. 1:121-131.

27. Arendshorst, W. J., and W. F. Finn. 1977. Renal hemodynamics in the rat before and during inhibition of angiotensin II. Am. J. Physiol. 233(4):F290-F297.

28. Hughes, M. L., and I. Ichikawa. Interglomerular heterogeneity of filtration fraction among superficial nephrons: fact or artifact. Kidney Int. In press.

29. Viets, J. W., W. M. Deen, J. L. Troy, and B. M. Brenner. 1978. Determination of serum protein concentration in nanoliter blood samples using fluorescamine or o-phthalaldehyde. Anal. Biochem. 88:513-421.

30. Deen, W. M., J. L. Troy, C. R. Robertson, and B. M. Brenner. 1973. Dynamics of glomerular ultrafiltration in the rat. IV. Determination of the ultrafiltration coefficient. J. Clin. Invest. 52:1500-1508.

31. Vurek, G. G., and S. E. Pegram. 1966. Fluorometric method for the determination of nanogram quantities of inulin. Anal. Biochem. 16: 409-419.

32. Führ, J., J. Kaczmarczyk, and C. D. Krüttgen. 1955. Eine einfache colorimetrische Methods zur Inulinbestimmung für Nierenclearanceuntersuchungen bei Stoffwechselgesunden und Diabetikern. Klin. Wochenschr. 33:729-730.

33. Colindres, R. E., W. S. Spielman, N. G. Moss, W. W. Harrington, and C. W. Gottschalk. 1980. Functional evidence for renorenal reflexes in the rat. Am. J. Physiol. 239:F265-F270.

34. Barajas, L. 1978. Innervation of the renal cortex. Fed. Proc. 37: 1192-1201.

35. Barajas, L., P. Wang, K. Powers, and S. Nishio. 1981. Identification of renal neuroeffector junctions by electron microscopy of reembedded light microscopic autoradiograms of semithin sections. $J$. Ultrastruct. Res. 77:379-385.

36. Dieterich, J. H. 1974. Electron microscopic studies of the innervation of the rat kidney. Z. Anat. Entwicklungsgesch. 145:169-186.

37. Gorgas, K. 1978. Innervation of the juxtaglomerular apparatus. In Peripheral Neuroendocrine Interaction. R. E. Coupland and W. G. Forssmann, editors. Springer-Verlag, New York. 144-152.
38. Barajas, L., K. Powers, and P. Wang. 1984. Innervation of the renal cortical tubules: a quantitative study. Am. J. Physiol. 247:F50F60.

39. Berns, A. S., and R. W. Schrier. 1984. The kidney in heart failure. In The Kidney in Systemic Disease. W. N. Suki and G. E. Knoyan, editors. John Wiley \& Sons Medical, New York. 569-596.

40. Barger, A. C., M. R. Liebowitz, and F. P. Muldowney. 1959. The role of the kidney in the homeostatic adjustments of congestive heart failure. J. Chronic Dis. 9:571-582.

41. Barger, A. C., F. P. Muldowney, and M. R. Liebowitz. 1959. Role of the kidney in the pathogenesis of congestive heart failure. Circulation. 20:273-285.

42. Schrier, R. W., M. H. Humphreys, and R. C. Ufferman. 1971. Role of cardiac output and the autonomic nervous system in the antinatriuretic response to acute constriction of the thoracic superior vena cava. Circ. Res. 29:490-498.

43. Gill, J. R., Jr., A. A. Carr, L. E. Fleischmann, A. G. T. Casper, and F. C. Bartter. 1967. Effects of pnetolinium on sodium excretion in dogs with constriction of the vena cava. Am. J. Physiol. 212:191-196.

44. Slick, G. L., G. F. DiBona, and G. J. Kaloyanides. 1974. Renal sympathetic nerve activity in sodium retention of acute caval constriction. Am. J. Physiol. 226:925-932.

45. Azer, M., R. Gannon, and G. J. Kaloyanides. 1972. Effect of renal denervation on the antinatriuresis of caval constriction. Am. J. Physiol. 222:611-616.

46. Davis, J. O., and R. H. Freeman. 1976. Mechanisms regulating renin release. Physiol. Rev. 56:1-5.

47. Thames, M. D. 1984. Renin release; reflex control and adrenergic mechanisms. J. Hypertension. 2(Suppl. 1):57-66.

48. Gregory, L. C., and I. A. Reid. 1984. Effect of renal denervation on the suppression of renin secretion by vasopressin in conscious dogs. Am. J. Physiol. 247(Renal Fluid Electrolyte Physiology 16):F881-F887.

49. Stella, A., and A. Zanchetti. 1984. Neural control of renin secretion. J. Hypertension. 2(Suppl. 1):83-88.

50. Davis, H. A., and E. W. Horton. 1972. Output of prostaglandins from the rabbit kidney: its increase on renal nerve stimulation and its inhibition by indomethacin. Br. J. Pharamacol. 46:658-675.

51. Stella, A., F. Calaresu, and A. Zanchetti. 1976. Neural factors contributing to renin release during reduction in renal perfusion pressure and blood flow in cats. Clin. Sci. Med. 51:453-461.

52. Zimmerman, B. G., and G. Gissleu. 1968. Patterns of renal vasoconstriction and transmitter release during sympathetic stimulation in the presence of angiotensin and cocaine. J. Pharmacol. Exp. Ther. 163:320-329.

53. Needleman, P., G. R. Marshall, and E. M. Johnson, Jr. 1974. Determinants and modification of adrenergic and vascular resistance in the kidney. Am. J. Physiol. 227:665-669. 